\title{
Role of environmental factors in autoantibody production - importance of a detailed analysis in a small cohort
}

\author{
Minoru Satoh ${ }^{* 1,2}$, Angela Ceribelli ${ }^{3}$ and Edward KL Chan ${ }^{3}$ \\ See related research by Muro et al., http://arthritis-research.com/content/13/6/R214
}

\begin{abstract}
In the previous issue of Arthritis Research \&

Therapy, Muro and colleagues reported a detailed epidemiologic analysis in central Japan on one of the new myositis-specific autoantibodies to MDA-5 (melanoma differentiation-associated gene 5), which is associated with clinically amyopathic dermatomyositis accompanying interstitial lung disease. The increasing prevalence of anti-MDA-5, higher prevalence in small rural towns, and geographical clustering in two areas along the Kiso River suggest a role of environmental factors associated with rural communities or the river/ water system or both. A detailed analysis of a small cohort may offer clues, which is ignored in multi-center studies, to the pathogenesis of systemic rheumatic diseases and autoantibody production.
\end{abstract}

Many autoantibodies to cellular constituents are useful biomarkers associated with a certain diagnosis or clinical manifestations or both. Autoantibodies in polymyositis/ dermatomyositis (PM/DM) have been actively studied in recent years, and several myositis-specific antibodies (MSAs) have been newly described.

In the previous issue of Arthritis Research \& Therapy, Muro and colleagues [1] reported a detailed epidemiologic analysis in central Japan on one of the recently described MSAs, anti-MDA-5 (melanoma differentiation-associated gene 5). This autoantibody was originally named anti-CADM-140 because of its association with clinically amyopathic DM (CADM) and the molecular size (approximately $140 \mathrm{kDa}$ ) of the target antigen [2].

*Correspondence: minoru.satoh@medicine.ufl.edu

'Division of Rheumatology and Clinical Immunology, Department of Medicine,

University of Florida, P.O.Box 100221, Gainesville, FL 32610-0221, USA

Full list of author information is available at the end of the article
The antigen was only recently identified as MDA-5, a cytoplasmic viral RNA receptor with RNA helicase activity [3]. MDA-5 is a part of anti-viral innate immunity. Stimulation of MDA-5 by its ligand induces type Iinterferon (I-IFN) production, and I-IFN also upregulates MDA-5. A strong association of anti-MDA-5 with CADM accompanying interstitial lung disease (ILD) was confirmed in several independent studies [3,4]. ILD in this subset is often rapidly progressive and resistant to treatment, making the detection of anti-MDA- 5 clinically important. Reports on anti-MDA-5 were limited to Japan and Korea until recently, when a study in the US confirmed the presence of this specificity [5].

MDA-5 as a target of autoantibodies in a subset of DM makes an attractive story because both viruses and I-IFN have been implicated in the pathogenesis of DM. Muro and colleagues [1] showed that, in recent years at their institute, an increasing prevalence of anti-MDA- 5 in a subset of patients was more prevalent in small rural towns compared with large cities. Furthermore, clustering of anti-MDA-5-positive cases to certain years and geographical areas is documented. In fact, five out of six and four out of four patients with anti-MDA-5 in 2002 and 2010, respectively, were from the two small areas along the Kiso River. These clustering patterns are consistent with the role of environmental factors associated with a rural community or the river/water system (or both) in the development of anti-MDA-5-positive CADM cases.

Among environmental factors in DM, ultraviolet (UV) exposure has been considered important since the percentage of DM within PM/DM and prevalence of anti-Mi-2 antibodies correlate with the UV index of the area [6]. In vitro upregulation of a major DM autoantigen, $\mathrm{Mi}-2$, by UV exposure supports this idea. However, given the history and occupation of the patients, the role of sun exposure seems unlikely in this cohort [1]. Seasonal difference in onset and relapse in PM/DM was reported in several studies and is another factor consistent with the role of environmental factors; seasonally skewed 
onset of PM/DM with anti-Jo-1, all anti-aminoacyl tRNA synthetases combined, anti-SRP (anti-signal recognition particle), and anti-7SL RNA has been reported [7]. Also, other studies show a difference in prevalence of PM/DM in rural versus urban communities but without a clear explanation [8]. Others reported an increased prevalence of anti-nuclear antibody among rural populations and suggested environmental factors such as certain crops, animals, or pesticides as potential causes [9]. The role of the river/water as environmental factors for production of anti-nuclear antibody has been considered mainly on the basis of pollution by heavy metals and other chemicals, consumption of contaminated fish, and diseases transmitted via water or water-related insects [10]. Whether the river/water plays a critical role in clustering in the study [1] remains to be clarified.

Large-scale multi-center studies have been a trend in recent years and are based on the assumption that environmental or minor genetic differences within the same country do not have significant effects. Samples and data from different institutes are pooled together; when the differences in prevalence of autoantibodies or other clinical features between institutions are found, they are usually interpreted as bias in recruitment or methodological heterogeneity between institutions. However, in other studies, regional differences in prevalence or geographical clustering of patients with $\mathrm{PM} / \mathrm{DM}$, scleroderma, or systemic lupus erythematosus or in production of certain autoantibodies [11,12] have been reported without clear explanation. Genetic heterogeneity within the same ethnicity, which may significantly affect autoantibody production pattern, is also well known. Some of the samples from this cohort [1] were included in a previous multi-center study in Japan, which reports 11\% prevalence of anti-MDA-5 in DM [13]. In contrast, prevalences of anti-MDA-5 in this small cohort are $27 \%$ overall, as high as $42 \%$ in the last 8 years, and $45 \%$ in rural areas [1]. This difference seems to be too much to be explained on the basis of recruitment bias or methodological errors, especially when the data show clustering in small areas.

As shown in Muro's study [1], the difference in genetic or environmental factors (or both) related to a specific geographic area should be carefully evaluated. This study may also offer clues that are not apparent in the large number of pooled samples in multi-center studies and that elucidate the pathogenesis of specific autoimmune disease and production of autoantibodies.

\section{Abbreviations}

CADM, clinically amyopathic dermatomyositis; DM, dermatomyositis; I-IFN, type I interferon; ILD, interstitial lung disease; MDA-5, melanoma differentiation-associated gene 5; MSA, myositis-specific antibody; PM, polymyositis; UV, ultraviolet.

\section{Competing interests}

The authors declare that they have no competing interests.

\section{Author details}

'Division of Rheumatology and Clinical Immunology, Department of Medicine, University of Florida, P.O.Box 100221, Gainesville, FL 32610-0221, USA.

2Department of Pathology, Immunology, and Laboratory Medicine, University of Florida, P.O.Box 100221, Gainesville, FL 32610-0221, USA. Department of

Oral Biology, University of Florida, Gainesville, FL 32610-0424, USA.

Published: 29 February 2012

\section{References}

1. Muro Y, Sugiura K, Hoshino K, Akiyama M, Tamakoshi K: Epidemiologic study of clinically amyopathic dermatomyositis and anti-melanoma differentiation-associated gene 5 antibodies in central Japan. Arthritis Res Ther 2011, 13:R214.

2. Sato S, Hirakata M, Kuwana M, Suwa A, Inada S, Mimori T, Nishikawa T, Oddis CV, Ikeda Y: Autoantibodies to a 140-kd polypeptide, CADM-140, in Japanese patients with clinically amyopathic dermatomyositis. Arthritis Rheum 2005, 52:1571-1576.

3. Sato S, Hoshino K, Satoh T, Fujita T, Kawakami Y, Kuwana M: RNA helicase encoded by melanoma differentiation-associated gene 5 is a major autoantigen in patients with clinically amyopathic dermatomyositis: association with rapidly progressive interstitial lung disease. Arthritis Rheum 2009, 60:2193-2200.

4. Hoshino K, Muro Y, Sugiura K, Tomita Y, Nakashima R, Mimori T: Anti-MDA5 and anti-TIF1-\{gamma\} antibodies have clinical significance for patients with dermatomyositis. Rheumatology (Oxford) 2010, 49:1726-1733.

5. Fiorentino D, Chung L, Zwerner J, Rosen A, Casciola-Rosen L: The mucocutaneous and systemic phenotype of dermatomyositis patients with antibodies to MDA5 (CADM-140): a retrospective study. J Am Acad Dermatol 2011, 65:25-34.

6. Love LA, Weinberg CR, McConnaughey DR, Oddis CV, Medsger TA Jr., Reveille $J D$, Arnett FC, Targoff IN, Miller FW: Ultraviolet radiation intensity predicts the relative distribution of dermatomyositis and anti-Mi-2 autoantibodies in women. Arthritis Rheum 2009, 60:2499-2504.

7. Leff RL, Burgess SH, Miller FW, Love LA, Targoff IN, Dalakas MC, Joffe MM, Plotz $\mathrm{PH}$ : Distinct seasonal patterns in the onset of adult idiopathic inflammatory myopathy in patients with anti-Jo-1 and anti-signal recognition particle autoantibodies. Arthritis Rheum 1991, 34:1391-1396.

8. Bernatsky S, Joseph L, Pineau CA, Belisle P, Boivin JF, Banerjee D, Clarke AE: Estimating the prevalence of polymyositis and dermatomyositis from administrative data: age, sex and regional differences. Ann Rheum Dis 2009, 68:1192-1196.

9. Kilburn KH, Warshaw RH: Prevalence of symptoms of systemic lupus erythematosus (SLE) and of fluorescent antinuclear antibodies associated with chronic exposure to trichloroethylene and other chemicals in well water. Environ Res 1992, 57:1-9.

10. Nyland JF, Fillion M, Barbosa F, Shirley DL, Chine C, Lemire M, Mergler D, Silbergeld EK: Biomarkers of Methylmercury Exposure Immunotoxicity among Fish Consumers in Amazonian Brazil. Environ Health Perspect 2011, 119:1733-1738.

11. Patrick M, Buchbinder R, Jolley D, Dennett $X$, Buchanan R: Incidence of inflammatory myopathies in Victoria, Australia, and evidence of spatial clustering. J Rheumatol 1999, 26: 1094-1100

12. Yamasaki Y, Yamada H, Nozaki T, Akaogi J, Nichols C, Lyons R, Chin Loy A, Chan EK, Reeves WH, Satoh M: Unusually high frequency of autoantibodies to PL-7 associated with milder muscle disease in Japanese patients with polymyositis/dermatomyositis. Arthritis Rheum 2006, 54:2004-2009.

13. Hamaguchi Y, Kuwana M, Hoshino K, Hasegawa M, Kaji K, Matsushita T, Komura K, Nakamura M, Kodera M, Suga N, Higashi A, Ogusu K, Tsutsui K, Furusaki A, Tanabe H, Sasaoka S, Muro Y, Yoshikawa M, Ishiguro N, Ayano M, Muroi E, Fujikawa K, Umeda Y, Kawase M, Mabuchi E, Asano Y, Sodemoto K, Seishima M, Yamada H, Sato S, et al.: Clinical correlations with dermatomyositis-specific autoantibodies in adult Japanese patients with dermatomyositis: a multicenter cross-sectional study. Arch Dermatol 2011, 147:391-398.

doi:10.1186/ar3739

Cite this article as: Satoh M, et al:: Role of environmental factors in autoantibody production - importance of a detailed analysis in a small cohort. Arthritis Research \& Therapy 2012, 14:109. 